\title{
Safe Tractor Access Platforms: From Guidance Material to Implementation
}

\author{
L. Day, G. Rechnitzer
}

\begin{abstract}
This article reports on the implementation of published guidelines for retrofitting tractors with safe access platforms, which were developed to reduce the risk of serious injuries and deaths associated with mounting and dismounting. Farmer interviews and engineering-based inspections of ten retrofitted tractors were conducted to gather information regarding benefits and disadvantages of the retrofitting and to assess the construction of the platforms. A scoring system was developed for platform retrofitting, and weighted scores between zero and ten were calculated for tractor access before and after retrofitting. Access was improved on all tractors, although to varying degrees. The average post-retrofit weighted score was 6.3 (range 2.6 to 9.7), compared with the pre-retrofit average of 0.9 (range 0.3 to 1.6). Five tractors received a post-retrofit score of 8.0 or higher. None of the lower-scoring tractors fully met the specifications for placement of the bottom step or rear wheel guard, two key characteristics for runover prevention. Other characteristics associated with a lower post-retrofit score included a low bottom step, high step rises, absence of colored nosing, and the front handrail space not being filled in. Platform retrofitting had little effect on tractor operations and substantially improved ease of access. This is the first published evaluation of a design-based solution for tractor runover injuries. This study shows that general guidelines for retrofitting of safe access platforms can be successfully applied. Mechanisms to increase adherence to the key criteria of bottom step positioning and rear wheel guarding should be included in future promotion.
\end{abstract}

Keywords. Accident prevention, Agricultural injuries, Agricultural machinery industry, Design, Passive protection, Tractor, Tractor access.

$\mathrm{T}$

ractors account for $15 \%$ to $45 \%$ of work-related fatalities among those employed in agriculture in many industrialized countries including Australia, the U.S., Canada, and New Zealand (Myers et al., 1998; Brison et al., 1998; Langley et al., 1997; Clarke and Coleman, 1995; Day, 1999). Historically, rollover events have comprised the large majority of tractor fatalities. Runover events comprise the next largest proportion of tractor fatalities, and in some areas, runover events now account for a greater proportion of tractor-related deaths than rollovers (Lough and Day, 2001).

Development and evaluation of appropriate interventions for tractor runover death and injury has lagged behind that for rollover events, possibly because runover events are not homogenous. At least five major types of runover events have been described in a detailed Australian case series study (table 1) (NOHSC, 2000). Falling from a moving tractor and being run over by the tractor or attached machinery was the most common,

Article was submitted for review in January 2004; approved for publication by the Journal of Agricultural Safety and Health of ASAE in March 2004.

Based on a report submitted to the Rural Industries Research and Development Corporation in 2002. Presented in part at the Sixth National Conference on Injury Prevention and Control, held March 16-18, 2003, in Perth, Australia.

The authors are Lesley Day, ASAE Member, Senior Research Fellow, and George Rechnitzer, Senior Research Fellow, Monash University, Accident Research Center, Melbourne, Australia. Corresponding author: Dr. Lesley Day, Accident Research Centre, Building 70, Monash University, Victoria 3800, Australia; phone: 03-9905-1811; fax: 03-9905-1809; e-mail: lesley.day@ general.monash.edu.au. 
Table 1. Main types of tractor runover fatal events in rank order (Australia, 1989-1992). [a]

\begin{tabular}{|c|c|}
\hline Runover Event Type & Associated Factors or Circumstances \\
\hline $\begin{array}{l}\text { Falling from a moving tractor and being run } \\
\text { over by the tractor or attached machinery. }\end{array}$ & Cabin doors opening and faulty brakes. \\
\hline Run over by an apparently parked tractor. & $\begin{array}{l}\text { Engaging in maintenance or handling attachments while } \\
\text { the engine is running, accidentally knocking tractor into } \\
\text { gear, or failed or inadequately secured hand brake. }\end{array}$ \\
\hline Pedestrian runover. & Commonly involve children. \\
\hline \multicolumn{2}{|l|}{ Starting a tractor from the ground. } \\
\hline Trying to mount a moving tractor. & Attempting to "catch" a tractor that had started to roll. \\
\hline
\end{tabular}

accounting for $42 \%$ of runover events, followed by being run over by an apparently parked tractor $(23 \%)$. A similar general pattern has also been observed in the U.S. (Myers et al., 1998).

There appears to be considerable scope for technical design-based solutions to some aspects of the runover problem. Deadman controls, as available on other kinds of mobile equipment, have been tested and found to be unsatisfactory by some authors (Buchele, 1994). However, the development of a mechanism to detect the operator getting on or off the tractor, which then stops tractor motion, is technically feasible. Some systems providing a degree of automatic protection are now appearing on new tractor models. Most tractors have a neutral start switch, and some tractors also require clutch depression, and less commonly, the operator to be in the seat, before the tractor will start.

Limited attention has been given to design-based solutions to the tractor runover problem for older tractors. Design and construction of a running board prototype has been undertaken in the U.S. (Buchele, 1994). This running board has been designed to guard the pinch points located in the space between the front and rear wheels and to provide stairway steps for mounting, thereby preventing tractor operators being caught under the wheels should they fall during mounting and dismounting. The running board strategy does not appear to have been systematically implemented or evaluated.

In response to the apparent risks associated with mounting and dismounting older tractors, the Australian Centre for Agricultural Health and Safety contracted leading safety engineers to produce a guidance note for the construction of safe access platforms for tractors (Davidson et al., undated). The safe access platform is intended to enable the operator to mount and dismount the tractor without stepping directly in front of the rear wheels. In addition, the platform is intended to reduce clutter, be slip resistant, provide hand holds, and prevent the operator from standing on the ground while the tractor is started. The platform design therefore addresses a number of the factors found to be associated with runover events. The guidance note does not include specific plans, due to the wide variation in tractor design. Rather, specifications are given and processes explained to assist in the construction of safe access platforms.

This guidance note has been distributed through farm safety networks, agricultural colleges, and at field days. It has been used by two local farm safety action groups in Victoria to retrofit older tractors with safe access platforms. An evaluation of the uptake and implementation of this initiative was conducted. The evaluation focused on the operational aspects of the retrofitted tractors and the design aspects of the platforms themselves.

\section{Methods}

A combination of qualitative methods and engineering-based inspections were used to (1) gather information from farmers regarding benefits and disadvantages of 
retrofitting and (2) assess the construction and installation of the platforms. Farmers were recruited via the group leaders of two farm safety action groups (FSAG) that had undertaken retrofitting. Five farmers were randomly selected from the nine who had had platforms retrofitted in each FSAG, and these ten farmers all agreed to participate. Funding limitations precluded inclusion of all 18 farmers.

Data were collected on the participant's property using an interview protocol and an engineering-based tractor inspection protocol. The interview included: amount of time required for participation and retrofitting, costs, tractor operations before and after retrofitting of the platform, and any benefits or disadvantages experienced since the retrofitting (table 2). The inspection protocol was developed from the guidelines published by the Australian Centre for Agricultural Health and Safety (Davidson et al., undated). The protocol included height and placement of the bottom step, rise and tread depth of the steps, presence and appropriateness of the handrail, integrity of the attachment points, and continued access to service points. The tractors were assessed with the wheels at the current track setting.

A scoring system was developed based on the specifications outlined in the guidelines. A tractor safety rating system under development at the time (Scott et al., 2002) provided the foundation, and the section relating to runover prevention was further developed to ensure that all guidelines were represented. Points were assigned to each of the specifications according to their potential contribution. Partial points were assigned if specifications were met within $10 \%$ or $20 \%$ of the recommendation. The two characteristics relating to keeping operators outside the wheel base should they fall were assigned $50 \%$ of the total available points. Characteristics relating to the prevention of slips and falls were assigned the remaining total points. The characteristic and points are shown in table 3. A pre-retrofit score was estimated by considering the access characteristics that would have applied before retrofitting. Three tractors did not have

Table 2. Farmer interview questions (safe tractor access platform evaluation, Victoria, 2001-2002).

How did you hear about the platform idea and how did you go about fitment?

Who designed the platform and what criteria were used?

How much of your time was required to fit the platform?

How much of your time was required prior to fitment for organization?

How much did the fitment cost you?

Were there any other costs associated with fitment, e.g., having tractor out of operation?

What kind of tasks did you use the tractor for before fitment?

Approximately how many hours per year was this tractor used prior to fitment?

Since platform fitment, is this tractor now used for tasks for which it was not previously?

If yes, what kind of tasks is the tractor now used for?

Since platform fitment, are you using this tractor more than you were before?

If yes, why is that, how much more are you using it, and are there specific tasks for which it is used more often?

Have you noticed any difference in using the tractor since the platform was fitted?

If yes, what are these differences?

What are the major advantages in having the platform fitted?

Have you noticed any disadvantages in having the platform fitted?

Do you think it would be tempting to carry passengers on the platform?

How long have you been farming?

What is the major commodity produced on your property? 
Table 3. Comparison of ten retrofitted platforms with the published recommendations (safe tractor access platform evaluation, Victoria, 2001-2002). [a]

\begin{tabular}{|c|c|c|c|c|c|}
\hline \multirow[b]{3}{*}{ Characteristic } & \multirow[b]{3}{*}{ Recommendation } & \multirow{2}{*}{\multicolumn{2}{|c|}{ Scoring Criteria }} & \multicolumn{2}{|c|}{ Tractors with: } \\
\hline & & & & \multirow{2}{*}{$\begin{array}{l}\text { Full Score } \\
\qquad(n)\end{array}$} & \multirow{2}{*}{$\begin{array}{l}\text { Part Score } \\
\qquad(n)\end{array}$} \\
\hline & & Criteria & Score & & \\
\hline \multicolumn{6}{|c|}{ For prevention of slips and falls } \\
\hline \multirow{3}{*}{$\begin{array}{c}\text { Bottom step } \\
\text { height }\end{array}$} & \multirow[t]{3}{*}{$\leq 400 \mathrm{~mm}$} & $\leq 400 \mathrm{~mm}$ & 1 & \multirow[t]{3}{*}{3} & \multirow[t]{3}{*}{2} \\
\hline & & $400-440 \mathrm{~mm}$ & 0.5 & & \\
\hline & & $441-480 \mathrm{~mm}$ & 0.25 & & \\
\hline \multirow[t]{2}{*}{ Step tread } & \multirow[t]{2}{*}{$\geq 240 \mathrm{~mm}$} & $\geq 240 \mathrm{~mm}$ & 1 & \multirow[t]{2}{*}{7} & \multirow[t]{2}{*}{1} \\
\hline & & $216-240 \mathrm{~mm}$ & 0.5 & & \\
\hline \multirow[t]{2}{*}{ Step rise ${ }^{[\mathrm{b}]}$} & \multirow[t]{2}{*}{$\leq 200 \mathrm{~mm}$} & $\leq 200 \mathrm{~mm}$ & 1 & \multirow[t]{2}{*}{3} & \multirow[t]{2}{*}{2} \\
\hline & & $200-220 \mathrm{~mm}$ & 0.5 & & \\
\hline Step material & $\begin{array}{l}\text { Non-slip grating with } \\
\text { max. ground visibility }\end{array}$ & Non-slip only & 0.5 & 9 & 1 \\
\hline Step lips & $\begin{array}{c}50 \mathrm{~mm} \text { lip front } \\
\text { and rear edge }\end{array}$ & Non-slip and lips & 1 & & \\
\hline Step nosing & Non-slip & Non-slip & 0.5 & 4 & \\
\hline $\begin{array}{l}\text { Step nosing } \\
\text { color }\end{array}$ & Bright & Bright & 0.5 & 2 & \\
\hline Front handrail & $\begin{array}{l}\text { Fully defining } \\
\text { access path }\end{array}$ & Fully defining & 0.5 & 7 & 3 \\
\hline $\begin{array}{l}\text { Front handrail } \\
\text { diameter }\end{array}$ & $30-40 \mathrm{~mm}$ & $\begin{array}{l}30-40 \mathrm{~mm} \\
27-44 \mathrm{~mm}\end{array}$ & $\begin{array}{c}1 \\
0.5\end{array}$ & 8 & \\
\hline $\begin{array}{c}\text { Front handrail } \\
\text { positioning }\end{array}$ & $\begin{array}{l}\text { Within tread of } \\
\text { bottom step }\end{array}$ & In position & 0.5 & 7 & \\
\hline $\begin{array}{l}\text { Front handrail } \\
\text { space }\end{array}$ & Filled in with mesh & Filled in & 0.5 & 5 & \\
\hline Handrail & $\begin{array}{l}\text { Present on both sides } \\
\text { of platform }\end{array}$ & $\begin{array}{l}\text { Both sides } \\
\text { One side }\end{array}$ & $\begin{array}{c}1 \\
0.5\end{array}$ & 7 & \\
\hline For prevention of ru & novers & & & & \\
\hline $\begin{array}{c}\text { Positioning of } \\
\text { bottom step }\end{array}$ & $\begin{array}{l}\text { Outer edge in line } \\
\text { with outside of } \\
\text { left rear wheel }\end{array}$ & $\begin{array}{c}\text { In line } \\
\text { Within } 50 \mathrm{~mm} \\
\text { Some wheel overlap }\end{array}$ & $\begin{array}{c}6 \\
3 \\
1.5 \\
\end{array}$ & 5 & 3 \\
\hline $\begin{array}{l}\text { Protection from } \\
\text { rear wheel }\end{array}$ & $\begin{array}{l}\text { Guard between } \\
\text { access platform } \\
\text { and rear wheel }\end{array}$ & $\begin{array}{l}\text { Full protection } \\
\text { Half protection } \\
\text { Some protection }\end{array}$ & $\begin{array}{c}3 \\
1.5 \\
0.5\end{array}$ & 5 & 4 \\
\hline
\end{tabular}

[a] Source: Davidson (1994/1995).

[b] Not relevant for three tractors that did not have steps.

steps for the post-retrofit assessment because the safe access platform was constructed onto the operator platform. Consequently, step rise was not applicable to these tractors. Other step characteristics such as tread, material, and nosing were assessed for the platform itself. Total pre-retrofit and post-retrofit scores for each tractor were weighted to a maximum score of 10 because the total possible scores were different for the three tractors without retrofitted steps.

Quantitative data (tractor type and age, farmer years of experience, tractor scores) were analyzed using the Statistical Package for Social Sciences (SPSS) version 11.0 to generate descriptive statistics (frequency distributions, medians, averages). The qualitative data gathered from the interviews were summarized. The average total cost per tractor was derived by converting the average farmer hours to a dollar term using 
standard wage costs (AUD\$14.70 per hour for skilled agricultural workers; Australian Bureau of Statistics, 2000) and adding this to the material costs and engineer charges.

\section{Results}

\section{Participant and Tractor Profiles}

Participating farmers (all male) were generally very experienced. Seven participants had been farming for 20 years or more, and the remaining three had been farming for between 5 and 14 years. Five participants had been farming for more than 30 years. The commodities produced reflected those typical of the two regions, with sheep, dairy, and beef being common.

The median tractor age was 22 years, and the median years of tractor ownership was 25 . Tractor makes and models, which were somewhat typical of older tractors on farms in Victoria, are shown in table 4, along with tractor age and years of ownership.

\section{Platform Retrofit Processes}

The two FSAG used different approaches to platform retrofitting. Group A (five farmers) opted for a workshop approach involving an engineer and the farmers, which also provided the opportunity for discussion of other safety issues. This FSAG employed a local engineer to attend retrofit workshops on a local property, design the platforms, and undertake their retrofitting with farmer assistance. Promotion included an occupational health and safety day at a local research farm (including a retrofit display), talks at Victorian Farmer Federation (VFF) meetings, information available at Victorian WorkCover Authority regional offices, personal contact by the FSAG leader, field day promotions and demonstrations, and media coverage. Group B (five farmers) opted for retrofitting contracted to two local engineering businesses, where participating farmers took their tractors for retrofitting. Promotion included a retrofit display and lucky draws at field days, talks at VFF and United Dairyfarmers meetings, and media coverage.

Three farmers across both areas heard about the idea from more than one source, indicating that multiple methods of promotion may be helpful.

The engineers used by both groups operated local general engineering steel fabrication businesses and were very experienced with metal work, agricultural equipment, and machinery maintenance and repairs. They all had copies of the guidelines, which they had been asked to follow. The overall high-quality construction of the retrofitted platforms reflected their expertise.

Table 4. Tractor profiles (safe tractor access platform evaluation, Victoria, 2001-2002).

\begin{tabular}{lccc}
\hline Make & Model & $\begin{array}{c}\text { Tractor Age at } \\
\text { Time of Retrofit } \\
\text { (years) }\end{array}$ & $\begin{array}{c}\text { Length of } \\
\text { Time Owned } \\
\text { (years) }\end{array}$ \\
\hline Case & 1394 & 14 & Unknown \\
Case International & 895 & 9 & 2 \\
Champion & $9 \mathrm{G}$ & 41 & 38 \\
David Brown & 880 & 37 & 37 \\
David Brown & 885 & 25 & 25 \\
David Brown & 1210 & 23 & Unknown \\
Iseki & 5000 & 19 & 4 \\
McCormick International & $\mathrm{A} 414$ & 35 & 35 \\
Massey Ferguson & 240 & 21 & 21 \\
Ursus & 3512 & 13 & Unknown \\
\hline
\end{tabular}




\section{Costs of Retrofiting}

The average actual cost of retrofitting (materials and engineering) was AUD\$185 per tractor for Group A. The time required by Group A farmers was 0.7 hours on average prior to retrofitting, and 5.4 hours on average for retrofitting. If this time is costed using the average hourly rate of pay for a skilled agricultural worker (AUD\$14.70; Australian Bureau of Statistics, 2000), then the total average cost of retrofitting per tractor was AUD\$275.

The average dollar cost of retrofitting (materials and engineering) was AUD\$446 per tractor for Group B. The time required by Group B farmers was 3 hours on average prior to retrofitting, making the necessary arrangements with the engineers and delivering the tractor to the engineering premises. No time was required for the retrofitting itself. If this time is costed using the average hourly rate of pay for a skilled agricultural worker, then the total average cost of retrofitting per tractor was AUD\$490.

The actual dollar cost to the farmers was heavily subsidized and ranged from nil to AUD\$200, with subsidies provided by federal, state, and local government.

\section{Operational Aspects of Retrofitted Tractors}

Platform installation had little effect on both the amount of time the tractors were used and on the tasks for which they were used, as reported during the farmer interviews. Two farmers reported increased tractor use since retrofitting, and one reported using the tractor for different tasks, although these changes were co-incidental to retrofitting. One farmer reported a change in the ratio of the type of tasks, with the tractor being used more frequently for loading and unloading objects after retrofitting. This was primarily due to the purchase of an additional tractor, but also because the retrofitted tractor was now more suitable for getting on and off frequently, which occurs during loading and unloading.

All farmers identified improved safety as an advantage, and six of the ten farmers (including some of the younger farmers) reported that the tractors were easier to get on and off. This was the aspect that most impressed the farmers:

- "Can't think how we did without it."

- "I can't underline the ease of use enough."

- "It's one of those things you don't realize how good it is until you experience it."

- "It's amazing how designers [of tractors] didn't think about getting on and especially off."

- "The difference is unbelievable."

One farmer reported that due to chronic back problems, he experienced difficulties with mounting and dismounting before retrofitting, as there was only room to put one foot onto the tractor and he had to swing his other leg up and through to the operator's area, which put intolerable strain on his back. The retrofit provided him with a platform onto which he could step with enough space for two feet, following which he could then get into the operator's seat. Without the retrofit, this farmer would have had to employ casual labor to feed out his stock.

Eight farmers did not experience any operational disadvantages. Two potential disadvantages were identified (i.e., getting bogged, and catching something on the platform), although neither of these problems actually occurred. The only actual disadvantage that was reported was mud build up on the platform.

When specifically asked about carrying passengers, five farmers reported that it could be tempting to carry passengers on the retrofitted platforms. There was no evidence to suggest that the practice of carrying passengers had increased following retrofitting. 


\section{Design Specifications of Retrofitted Platforms}

Step dimension recommendations overall were not closely followed, particularly with respect to height of the bottom step and tread depth. Three of the ten retrofitted tractors met the criteria for height of the bottom step, and a further two exceeded it by less than $10 \%$ (tables 3 and 5). The step height for the remaining five tractors ranged from 490 to $570 \mathrm{~mm}$. Seven tractors met the criteria for tread depth, and a further one was within a $10 \%$ margin (tables 3 and 5). The remaining two tractors had tread depths of 165 and $190 \mathrm{~mm}$.

Although not specifically mentioned in the guidelines, the design and positioning of some steps did not provide unimpeded access, although access had been improved. For example, "split-leveling" of the top step can be seen in figure 1 .

Handrail recommendations were generally well met. Attachment of the handrails was adequate with the exception of one tractor, where it appeared that the front handrail had been welded onto the rollover protective structure frame, potentially compromising the structural integrity of the frame.

Five of the ten retrofitted tractors fully met the criteria for positioning of the bottom step, a key feature for reducing the risk of runover in the event of falling from the platform (tables 3 and 5). Among those that did not, the distance between the outer edge of the bottom step and the edge of the rear wheel ranged from 100 to $350 \mathrm{~mm}$.

The guidelines recommend that a guard be placed between the access platform and the tractor mudguard, to prevent contact between the rear wheel and the operator. However, the mudguard itself could be expected to prevent this contact if it covers the full width of the tire face. Adequate protection was provided by the rear wheel mudguard on three tractors, and by a guard attached to the platform on a further two tractors. This guard was formed from the rear handrail attached to the platform and with the resulting space filled in with wire mesh (fig. 2).

Table 5. Post-retrofit scores for individual tractors (safe tractor access platform evaluation, Victoria, 2001-2002).

\begin{tabular}{lcccccccccc}
\hline & \multicolumn{10}{c}{ Tractor } \\
\cline { 2 - 11 } Characteristic & 1 & 2 & 3 & 4 & 5 & 6 & 7 & 8 & 9 & 10 \\
\hline Bottom step height & 0 & 0 & 0 & 0 & 0 & 1 & 0.5 & 0.5 & 1 & 1 \\
Step tread & 1 & 0 & 1 & 0 & 1 & 0.5 & 1 & 1 & 1 & 1 \\
Step rise ${ }^{[a]}$ & 0.5 & 0 & & 0 & 0.5 & 1 & 1 & 1 & & \\
Step material and lips & 1 & 1 & 0.5 & 1 & 1 & 1 & 1 & 1 & 1 & 1 \\
Step nosing & 0.5 & 0.5 & 0.5 & 0.5 & 0 & 0 & 0 & 0 & 0 & 0 \\
Step nosing color & 0 & 0 & 0 & 0 & 0 & 0 & 0 & 0 & 0.5 & 0.5 \\
Front handrail defines access & 0.5 & 0.5 & 0.5 & 0.5 & 0.5 & 0 & 0 & 0 & 0.5 & 0.5 \\
Front handrail diameter & 1 & 0 & 0 & 1 & 1 & 1 & 1 & 1 & 1 & 1 \\
Front handrail position & 0 & 0.5 & 0.5 & 0.5 & 0.5 & 0.5 & 0 & 0 & 0.5 & 0.5 \\
Front handrail space & 0.5 & 0 & 0 & 0 & 0.5 & 0.5 & 0 & 0 & 0.5 & 0.5 \\
Handrail each side & 1 & 1 & 0.5 & 1 & 1 & 0.5 & 0.5 & 1 & 1 & 1 \\
Position bottom step & 1.5 & 1.5 & 0 & 0 & 1.5 & 6 & 6 & 6 & 6 & 6 \\
Protection from rear wheel & 0.5 & 1.5 & 1.5 & 0 & 1.5 & 3 & 3 & 3 & 3 & 3 \\
\hline Total & 8 & 6.5 & 5 & 4.5 & 9 & 15.5 & 14 & 14.5 & 16 & 16 \\
Total possible & 17.5 & 17.5 & 16.5 & 17.5 & 17.5 & 17.5 & 17.5 & 17.5 & 16.5 & 16.5 \\
Weighted score $[\mathrm{b}]$ & 4.6 & 3.7 & 3.0 & 2.6 & 5.1 & 8.6 & 8.0 & 8.3 & 9.7 & 9.7 \\
\hline
\end{tabular}

[a] Not relevant for tractors 3, 9, and 10, which did not have steps.

[b] Scores weighted to a maximum of 10 . 

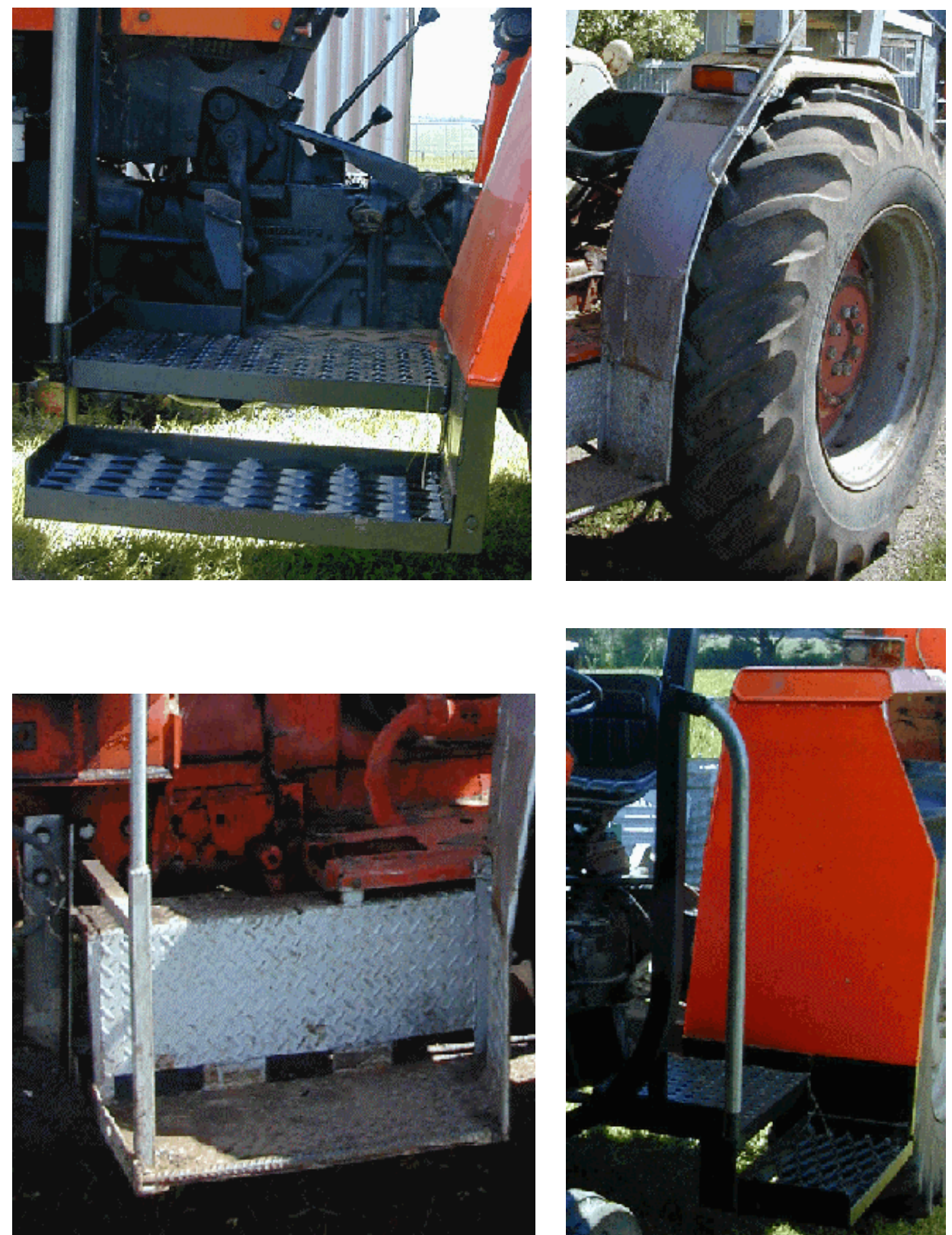

Figure 1. Positioning of steps with respect to driver platform and mudguard width (safe tractor access platform evaluation, Victoria, 2001-2002).

There was a tendency on some retrofitted tractors to be unnecessarily constrained by the dimensions and positioning of the driver platform and the mudguard width. This resulted in the outer edge of the bottom step being recessed with respect to the outer edge of the rear wheel, and in insufficient guarding of the rear wheel by the mudguard (fig. 2, left). 

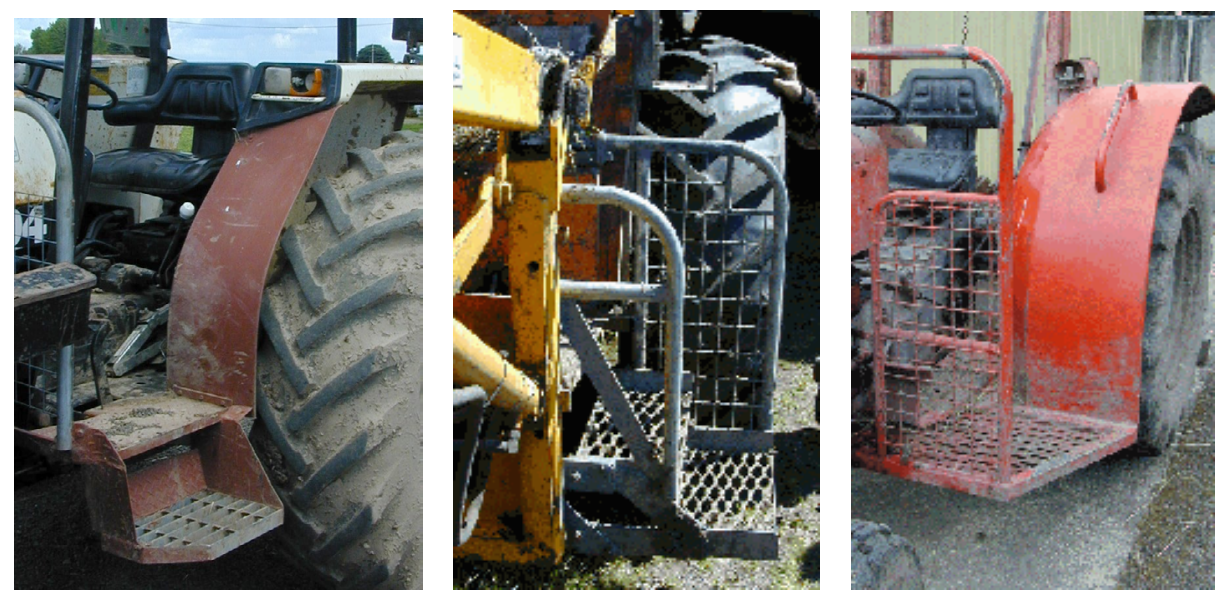

Figure 2. Examples of guarding of rear wheel: (left) incomplete guarding of rear wheel, (middle) complete guarding of rear wheel by rear handrail and wire mesh, and (right) complete guarding with mudguard (safe tractor access platform evaluation, Victoria, 2001-2002).

Recommendations for the attachment and bracing of the access platforms, underframe clearance, and access to service points were well met. Access on the opposite side of the tractor had been prevented as recommended on three tractors.

\section{Effect on Access}

Access scores improved on each tractor, compared with that available prior to retrofitting (table 6). The average post-retrofit score was 6.3, compared with the average pre-retrofit score of 0.9. Figure 3 shows the pre- and post-retrofit sides of two example tractors, using the pre-retrofit side as a proxy for the type of access available prior to retrofitting.

Five tractors received a post-retrofit weighted score of 8.0 or higher (table 6). For these tractors, the risk of being runover if the operator fell from the tractor while moving had been adequately addressed, but there was some residual risk of falling off while mounting due to the handrail placement combined with absence of non-slip step edges. In comparison, the risk of being run over in the event of a fall had not been addressed adequately by any of the remaining five lower-scoring tractors. The bottom step outer edges were not level with the edge of the rear wheel, nor were the rear tires adequately guarded on any of these five tractors (e.g., fig. 2, left). Other characteristics associated with a lower score on three or more of these five tractors included height of the bottom step, step rise, colored nosing, and the front rail space not being filled in.

\section{Discussion}

The results presented here have shown that the initial implementation of safe tractor access platform retrofitting appears relatively successful. Two different retrofitting processes (a workshop involving the tractor owners, or contracting to a local engineering business) were developed and tested, and both proved to be efficient and affordable for the participating farmers, engineers, and farm safety action group leaders. The two different processes each have advantages that may appeal to different farmers, engineers, and local groups. One process had the advantage of being slightly less costly and possibly increasing knowledge and skills. The other process had the advantage of convenience by requiring very little of the tractor owner's time. 

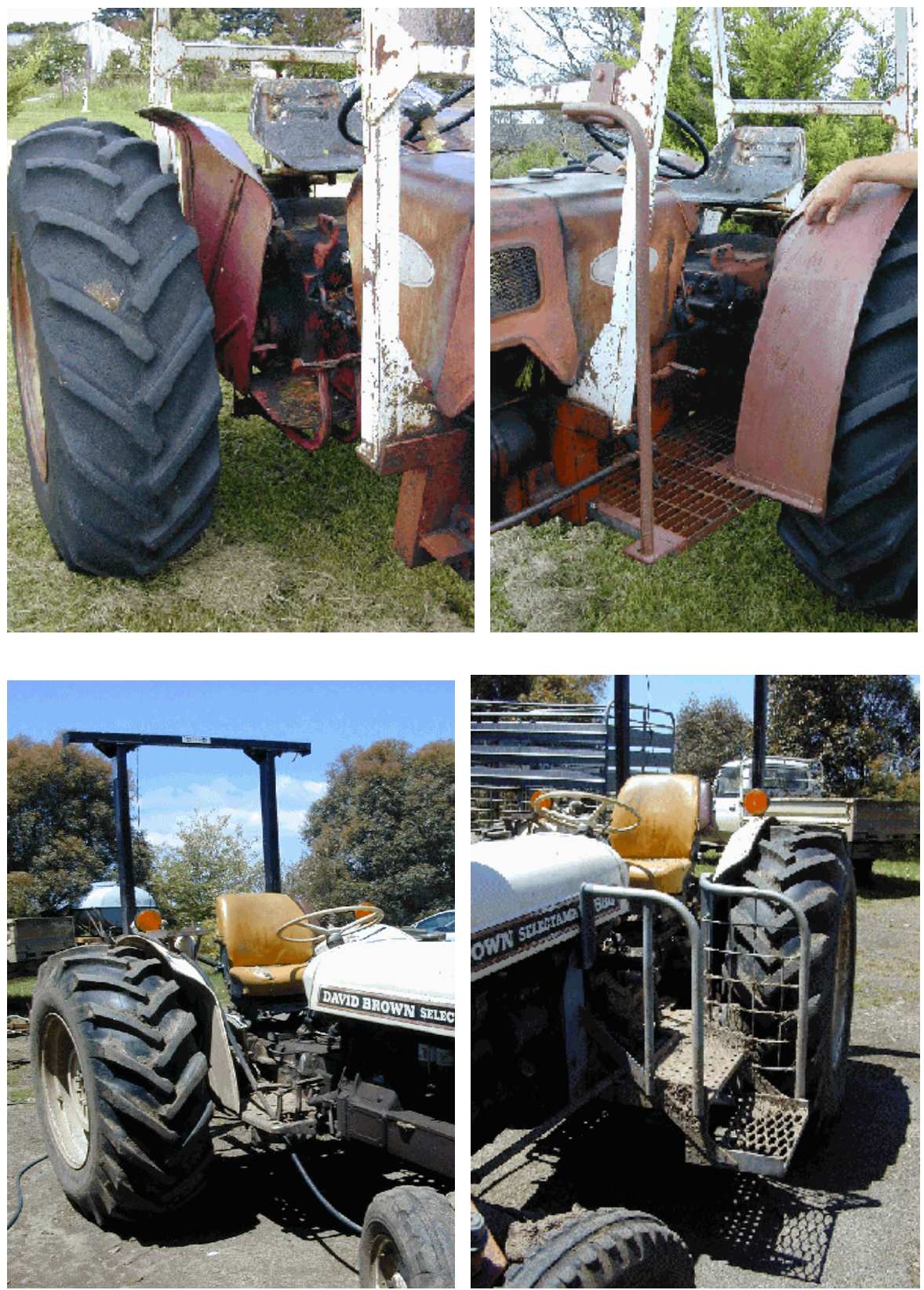

Figure 3. Examples of (left, top and bottom) pre-retrofit and (right, top and bottom) post-retrofit tractors (safe tractor access platform evaluation, Victoria, 2001-2002).

It appeared that the approach of Group A was more cost-effective than that of Group B, even when participating farmer time was taken into account. However, the Group A tractors were characterized by inadequate coverage of the rear wheel. Since the initial retrofitting workshops in this area, the cost per tractor has risen due to an increased 
Table 6. Comparison of weighted scores before and after retrofitting of safe tractor access platforms (Victoria, 2001-2002).

\begin{tabular}{|c|c|c|}
\hline Weighted Score ${ }^{[a]}$ & Before Retrofitting & After Retrofitting \\
\hline Tractor 1 & 0.6 & 4.6 \\
\hline Tractor 2 & 0.6 & 3.7 \\
\hline Tractor 3 & 0.9 & 3.0 \\
\hline Tractor 4 & 0.3 & 2.6 \\
\hline Tractor 5 & 0.9 & 5.1 \\
\hline Tractor 6 & 1.3 & 8.6 \\
\hline Tractor 7 & 1.6 & 8.0 \\
\hline Tractor 8 & 0.3 & 8.3 \\
\hline Tractor 9 & 1.3 & 9.7 \\
\hline Tractor 10 & 1.6 & 9.7 \\
\hline
\end{tabular}

[a] Scores weighted to a maximum of 10 .

emphasis on rear wheel coverage. The average cost for a recently retrofitted group of tractors in this area was AUD\$310. When farmer time is taken into account, the revised cost for Group A is AUD\$400 per tractor, which is similar to the cost for Group B (AUD $\$ 490$ on average per tractor). It should be noted that the actual cost per tractor can vary, not only according to the process used, but also according to the degree of difficulty involved and the type and amount of materials needed for any particular tractor.

The retrofitted platforms had very little effect on tractor operations with respect to the tasks for which the tractor was used and the amount of operational time. However, the platforms had a substantial effect on the ease of access, and it was this aspect that most impressed the participating farmers. This tangible outcome experienced on a day-to-day basis could be promoted as an additional benefit of platform retrofitting.

The specifications for the platform retrofit are intended to both reduce the risk of a fall from the steps or platform, and to reduce the risk of a runover should the operator fall from a moving tractor. The array of these required design changes highlights the extent of the inadequacy of the original tractor designs in providing for safe and ergonomically sound access.

The step/platform factors associated with decreasing the risk of a fall include the step height and dimensions, handrails, non-slip materials, and lips on step edges. The retrofitted tractors did not meet the bottom step height specification particularly well. It may be that farmers are concerned about clearance issues if the bottom step is too low, as this issue was mentioned as a potential problem by two of the participating farmers. There may be a design solution that could meet this concern and still meet the height specification for tractor access, such as hinging the bottom step as suggested in the guidelines. For those tractors that actually had steps (as opposed to an extended platform at the operator level), the dimensions for step tread and rise were generally fairly close to those specified. Lip edges were mostly satisfactory.

The recommended material (grating) for step construction was used for the bottom step on eight of the ten tractors. Other materials used are all commonly marketed as slip resistant. However, some of these may not perform well in this setting, e.g., perforated plate may become covered with grass and other organic debris too large to pass through the perforations. Similarly, some of the non-slip materials used on the step nosing may not perform well in this setting. Few tractors had brightly colored nosing, which could be difficult to maintain due to wear on the step edges.

Handrails generally met the guidelines. There was a tendency on some tractors to position the upright portion of the handrail in the tread of the second (or top) step rather than in the tread of the bottom step (as indicated). 
The step/platform factors associated with decreasing the risk of a runover (should the operator fall from a moving tractor) include the positioning of the outer edge of the bottom step and the guarding of the rear wheel. The key criteria of positioning the outer edge of the bottom step level with the outer edge of the rear wheel was met by only half the tractors. Further, the rear wheel was adequately guarded on only half the tractors. Concern regarding mud build up on the inside of a mudguard can be countered by replacing it with a wire guard on the platform edge nearest the rear wheel (fig. 2, middle). Closer attention to these two specifications would have increased the post-retrofit scores of some retrofitted tractors.

There was no evidence to indicate that increased passenger carriage as a result of the retrofitted platforms is likely. Any increased passenger carriage may be at least partially offset by the probable decrease in runover risk, should a passenger fall from a platform or steps that meet the key criteria of extending to the outer edge of the rear wheel. Farmers choosing to have their tractors retrofitted should receive written advice regarding use of the tractor following retrofitting, including advice against the carrying passengers. The application of a "no passenger" decal onto retrofitted platforms could be considered.

Safe tractor access platforms could be promoted through a wide range of networks including rural media, farmer organizations and groups, local or county government, local offices of relevant organizations and government departments, engineers, and farm machinery dealers. Promotion should include opportunities for farmers to actually try out retrofitted platforms by having displays at field days and shows, engineer workshops, farm machinery dealers, and other relevant locations. Promotional material should emphasize ease of access, reduced physical demand, reduction of runover risk, and the relatively low cost.

Reduction, through design features, of the risk of falling, and the risk of a runover in the event of a fall, are two strategies for the reduction of runover events. A complete analysis of strategies for runover prevention is outside of the scope of this study. However, it is worth noting that since a significant proportion of runover events involve tractors with an ineffective parking brake, regular testing and maintenance of the parking brake would also play a role in runover prevention. This could be incorporated into the platform retrofitting process. Further, the use of technical advances in new tractors that increase the automatic protection of tractor operators from runover events would also contribute to future reductions as the tractor fleet is replaced with newer models. Continuing education and training in the management of occupational health and safety risk on farms would also play a role, as in any well designed occupational health and safety program (National Committee for Injury Prevention and Control, 1989; Smith, 2001).

\section{Conclusion}

This is the first published evaluation of a design-based solution for tractor runover injuries. This study has identified that general guidelines for retrofitting of safe access platforms can be successfully applied. Mechanisms to increase adherence to the key criteria of bottom step positioning and rear wheel guarding should be included in future promotion. This initiative has the potential to not only substantially reduce the risk of tractor runover events, but also to reduce the physical demand of frequent mounting and dismounting of tractors, thereby improving the work environment for tractor operators and potentially increasing productivity. There may also be implications for access design for new tractors to ensure that the next generation of tractors has optimal design for ergonomically sound and safe access. 


\section{Acknowledgements}

We are very grateful to Jill Tucker and Graeme Prince, the respective leaders of the Wellington and Colac Farm Safety Action Groups, for their assistance with the field work for this project. We are also grateful to the participating farmers for their time, provision of access to their tractors, and for their hospitality during our site visits. The engineers, Norm Johnston (Longford Mechanical Engineering), Mark Blacket (Birregurra Engineering) and Greg Jenkins (Coweld Engineering), were also willing participants in this research. Geoff McDonald (Geoff McDonald and Associates Pty Ltd) provided valuable advice regarding the guideline specifications. This study was funded by the Rural Industries Research and Development Corporation.

\section{References}

Australian Bureau of Statistics. 2000. Employee earnings and hours. Catalogue No. 6306.0 Canberra, Australia: Australian Bureau of Statistics.

Brison, R., W. Pickett, L. Hartling, and R. Matys. 1998. Fatal farm injuries in Canada, 1990-1996. Saskatoon, Sask.: Canadian Agricultural Injury Surveillance Program.

Buchele, W. F. 1994. Running boards for farm tractors. ASAE Paper No. 945009. St. Joseph, Mich.: ASAE.

Clarke, L., and R. Coleman. 1995. Profile of farm health and safety: A report to Farmsafe Australia. Moree, Australia: Australian Agricultural Health Unit.

Davidson, A. 1994/1995. National tractor safety project final report. Moree, Australia: Australian Agricultural Health Unit.

Davidson, A., G. McDonald, J. Tullberg, and S. Collie. (undated). Safe tractor access platform. Moree, Australia: Australian Agricultural Health Unit.

Day, L. 1999. Farm work related fatalities among adults in Victoria, Australia: The human cost of agriculture. Accident Analysis and Prevention 31(1-2): 153-159.

Langley, J. D., J. Clarke, S. W. Marshall, P. C. Cryer, and J. Alsop. 1997. Tractor fatalities and injury on New Zealand farms. J. Agric. Safety and Health 3(4): 237-251.

Lough, J., and L. Day. 2001. Farm Injury Surveillance Tools (FIRST). Annual Report 2000, vol. 3(1). Melbourne, Australia: Monash University Accident Research Centre.

Myers, J., K. Snyder, D. Hard, V. Casini, R. Cianfrocco, J. Fields, and L. Morton. 1998. Statistics and epidemiology of tractor fatalities - a historical perspective. J. Agric. Safety and Health 4(2): 95-108.

National Committee for Injury Prevention and Control. 1989. Injury Prevention: Meeting the Challenge. New York, N.Y.: Oxford University Press.

NOHSC. 2000. Work-related fatalities involving tractors in Australia, 1989 to 1992. Sydney, Australia: National Occupational Health and Safety Commission.

Scott, M., R. Williams, L. Day, G. Rechnitzer, P. Walsh, and S. Boyle. 2002. Safe tractor assessment rating system: Technical reference document. Melbourne, Australia: Monash University Accident Research Centre. Available at: www.general.monash.edu.au/muarc/stars.htm. Accessed on 12 March 2004.

Smith, G. S. 2001. Public health approaches to occupational injury prevention: Do they work? Injury Prevention 7(suppl. I): 3-10. 
